Improvement of the wear resistance of EN8 steel by application of alternating magnetic field treatment

Sufyan Akram ${ }^{1}$, Anatolii Babutskyi ${ }^{1,2}$, Andreas Chrysanthou ${ }^{1}$, Diogo Montalvão ${ }^{3}$, Mark J. Whiting ${ }^{4}$ and Om Prakash Modi $^{5}$

${ }^{1}$ School of Physics, Engineering and Computer Science, University of Hertfordshire, Hatfield, AL109AB, United Kingdom (

${ }^{2}$ G.S. Pysarenko Institute for Problems of Strength, National Academy of Sciences of Ukraine, Kyiv, 01014, Ukraine

${ }^{3}$ Department of Design and Engineering, Faculty of Science and Technology, Bournemouth University, Poole House, Talbot Campus, Fern Barrow, Poole BH12 5BB, United Kingdom (montalvao@bournemouth.ac.uk)

${ }^{4}$ Department of Mechanical Engineering Sciences, University of Surrey, Guildford, Surrey GU2 7XH, United Kingdom (m.whiting@surrey.ac.uk)

${ }^{5}$ Department of Materials Science and Metallurgical Engineering, Maulana Azad National Institute of Technology, Bhopal, 462003, India and formerly at CSIR-Advanced Materials \& Processes Research Institute, Bhopal, 462026, India (omprakashmodi56@gmail.com)

Friction, Wear, Medium Carbon Steel, Magnetic Field Treatment

\begin{abstract}
In the present paper, the tribological properties of untreated and magnetically treated EN8 medium-carbon steel were studied. Tribological tests were performed using a pin-on-disc friction and wear tester. The alternating magnetic field treatment has led to a reduction in the coefficient of friction by $18 \%$ and of the wear rate by $41 \%$ and to decreases in the surface roughness and the wear scar width by $30 \%$ and $12 \%$ respectively. Examination by means of transmission electron microscopy attributed these results to increased dislocation mobility and migration to the surface as a result of alternating magnetic field treatment leading to an increase in the Vickers microhardness and to an increase in compressive residual stresses at the surface.
\end{abstract}

\title{
Introduction
}

Owing to its good mechanical performance, high wear resistance and low cost [1-3], EN8 steel is widely used in automotive applications for components such as gears, rods, bolts and shafts. Such demanding applications can lead to failure of these components the performance of which can be improved by reducing friction either (i) by using liquid or solid lubricants between the working faces $[4,5]$ or (ii) by modification of the applied materials and their properties [5-7]. In the case of the latter approach, various types of surface modification techniques can be used to improve the wear resistance of alloys including nitriding, carburizing and shot-peening [8-10]. While nitriding and carburizing form a harder surface layer, along with shot-peening they also induce compressive residual stresses at the surface thus 
increasing the hardness of the material [11]. These techniques may require specialised equipment, high temperatures and can be time-consuming [8].

During recent years, there has been growing interest in the use of magnetic fields to improve the mechanical properties and the tribological behaviour of metallic alloys [2, 12-17]. While most of these investigations conducted tribological tests in the presence of a magnetic field, $\mathrm{Xi}$ et al. [17] examined the effect of pulsed magnetic field treatment on the tribological behaviour of AISI 1045 steel. It was reported that the coefficient of friction decreased by $16.4 \%$ after the application of a pulsed magnetic field of $320 \mathrm{Gs}$ about $30 \mathrm{~s}$ prior to the friction wear test. Xi et al. [17] attributed the improvements of the tribological properties to increased dislocation density and refined ferrite. Further studies have shown that the wear resistance of high-speed steel [18] mild steel [19], medium steel [20] and bearing steel [16] improved as a result of magnetic field treatment. By applying a magnetic field during testing, Wei et al [21] and Tharajak and Nicomrat [22] observed a decrease in the friction coefficient. They attributed their observations to the applied magnetic field leading to oxidation on the surface and promoting finer wear debris particles. However, the use of components while in service in the presence of a magnetic field may be impractical; instead it would be of benefit to develop methods based on magnetic field treatment. The work which is reported in this paper differs from earlier work in that it applies an alternating magnetic field treatment which uses simpler equipment and is more costeffective in comparison with pulsed magnetic treatment. In addition, more work is necessary in order to fully understand the effects of processes that use magnetic fields. In the present study, the exposure of EN8 steel to a magnetic field is investigated. EN8 steel is a standard load-bearing steel that is typically used in applications such as automotive components, axles, shafts etc. Specimens were treated and tested using pin-on-disc testing under lubricated conditions. The wear scar tracks were examined using scanning electron microscopy (SEM). In addition, residual stress (by means of X-ray diffraction), micro- and nano-hardness measurements were conducted. Observations of the magnetic domain structures were studied before and after treatment. Lastly, microstructure changes were studied using transmission electron microscopy (TEM).

\section{Experimental Methodology}

Cold-rolled EN8 steel was used in this investigation. The composition of EN8 steel (in wt.\%) was as follows: C, 0.36 0.44; Mn, 0.6 - 1.0; Mo, 0.15; P, 0.05; Si, 0.1 - 0.4; S, 0.05; Fe, balance.

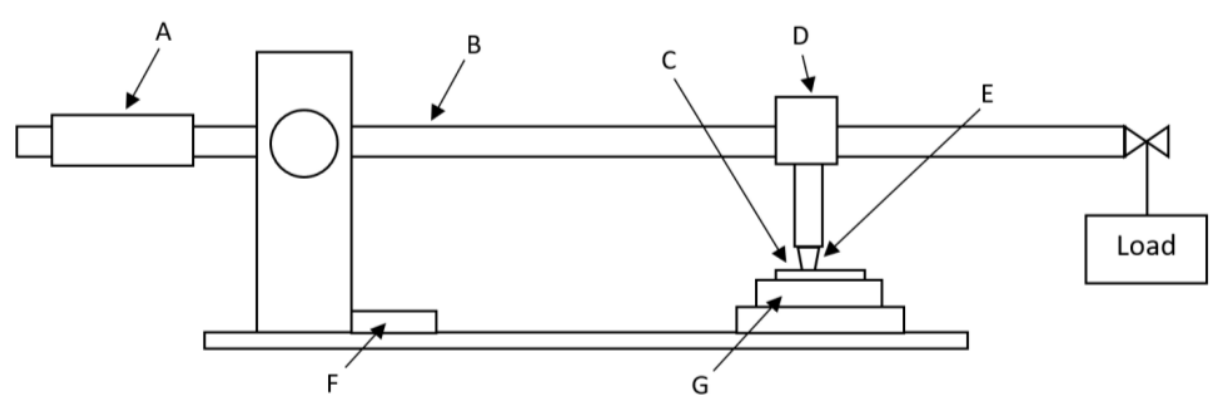

Figure 1 Schematic of POD 2 pin-on-disc tester balance weight (A), load beam (B), sample (C), load cell (D), wear pin (ball) \& holder (E), wear track radius micrometre adjustment $(F)$ and rotating sample table $(G)$. 
For the preparation of the pin-on-disc samples, a $27 \mathrm{~mm}$ diameter EN8 steel bar was sliced to a thickness of 3.1 mm using a Struers Secotom-10 cutting machine under a very low feed rate. Prior to testing, the samples were ground and then finely polished using a $0.3 \mu \mathrm{m}$ diamond suspension.

The pin-on-disc samples were tested under sliding conditions using a POD 2 pin-on-disc tester (Teer Coatings Ltd.). Figure 1 shows a schematic of the test set up. The samples were tested under lubricated conditions using sunflower oil as a lubricant at a linear velocity of $50 \mathrm{~mm} / \mathrm{s}$ for $60 \mathrm{~min}$ at ambient temperature of $22^{\circ} \mathrm{C}$. The contact ball bearings used in the tests had diameter of $5 \mathrm{~mm}$ and were made of AISI52100 bearing steel with a Rockwell hardness, HRC, of 60-67 and surface roughness Ra of $20 \mathrm{~nm}$. A vertical load of $10 \mathrm{~N}$ was applied to the EN8 steel. The equipment has a friction force measurement sensitivity of $0.02 \mathrm{~N}$. The pin-on-disc samples were cleaned thoroughly with acetone before and after testing. A precision digital scale with an accuracy of $\pm 0.1 \mathrm{mg}$ was used to weigh the samples before and after testing.

The specific wear rates of the materials were obtained by using the formula:

$$
W=\frac{\Delta w}{L \rho F}
$$

where $W$ is the specific wear rate in $\mathrm{mm}^{3} / \mathrm{Nm}, \Delta w$ is the weight loss measured in grams, $L$ is the sliding distance in $\mathrm{m}$, $\rho$ is the density of the worn material in $\mathrm{g} / \mathrm{mm}^{3}$ and $F$ is the applied load in $\mathrm{N}$.

Specimens of the same geometry were used for X-ray diffraction (XRD), microhardness testing and nanoindentation testing. Microhardness tests were performed using a Struers DuraScan 20 microhardness tester at a load of $1 \mathrm{~N}$. The microhardness values were obtained by averaging at least 40 indentations across two radii of the sample. Nanoindentation measurements were performed using a Micromaterials NanoTest Vantage nanoindentation platform 3 with a Diamond Berkovich indenter. 100 indentations were conducted using a 10 by 10 grid matrix with $100 \mu \mathrm{m}$ spacing between each indent. A load of $50 \mathrm{mN}$ with a load hold time of 10 seconds, a dwell period of 20 seconds and an unloading time of 5 seconds was performed. Nanoindentation was conducted to measure the hardness and to determine the $\mathrm{H}^{3} / \mathrm{E}^{2}$ ratio, where $\mathrm{H}$ is the hardness and $\mathrm{E}$ is the elastic modulus. The elastic modulus of the sample was calculated using the following equation:

$$
E=\frac{1-v_{s}^{2}}{\frac{1}{E_{r}}-\frac{1-v_{i}^{2}}{E_{i}}}
$$

where $v_{s}$ and $v_{i}$ are the Poisson's ratio of the sample and the Berkovich indenter, $E_{i}$ is the elastic modulus of the indenter and $E_{r}$ is the reduced modulus of the sample after indentation. Residual stress (RS) analyses were conducted using a Bruker D8 Advance X-ray diffractometer with Cu-Ka radiation of wavelength $1.540549 \AA$ and radiation energy of $8.04 \mathrm{keV}$. The tube voltage and current were set at $40 \mathrm{kV}$ and $40 \mathrm{~mA}$, respectively. The (222) iron peak was used at $2 \theta=137^{\circ}$. The residual stress was calculated by using the Sliding Gravity method (which is the preferred method for 
industrial products) [23]. To improve the accuracy of the phase analysis, background subtraction, smoothing, $\mathrm{K} \alpha_{2}$ correction, absorption correction and polarization corrections were performed. The stress model used was based on normal stress. All the data were analysed using the Leptos software version 7.9. Two samples that had been polished to a $0.3 \mu \mathrm{m}$ finish using a diamond suspension were used for RS measurements. A total of 5 measurements were obtained at different tilt positions of $0^{\circ}, 11.25^{\circ}, 22.5^{\circ}, 33.75^{\circ}$ and $45^{\circ}$ for each sample. Exactly the same samples were used for the RS measurements; following measurements in the untreated condition, the same samples underwent alternating magnetic field treatment before further RS analysis.

Topography observations of the wear scar width (with and without treatment) were conducted using a JEOL JSM5700F CarryScope scanning electron microscope (SEM) equipped with energy-dispersive X-ray microanalysis (EDAX). The surface profile and the average surface roughness measurements of the wear tracks were performed using a Mitutoyo Surftest SJ-500 2D surface profiler. The liner surface profile was measured by the Mitutoyo surface profiler using a stylus profilometer with a styles tip radius and angle of $2 \mu \mathrm{m}$ and $60^{\circ}$ respectively. Magnetic force microscopy (MFM) was conducted using a Nanosurf Easyscan 2 to observe changes in the magnetic domain structure. A Neodynium magnet MagneticMulti74-G cantilever was used to scan the magnetic domains of EN8 steel. The scanning range was $50 \mu \mathrm{m}$ by $50 \mu \mathrm{m}$ and the height of the probe for the measured surface was $100 \mathrm{~nm}$. To analyse changes in the dislocation structure, transmission electron microscopy (TEM) was operated at $200 \mathrm{kV}$ using a FEl/Philips CM-20 (Philips Electron Optics, Eindhoven, The Netherlands). The EN8 steel TEM samples were prepared using a TESCAN LYRA3 (Tescan Orsay Holding, Brno, Czech Republic) equipped with a high-performance CANION FIB system for precise cross-section cutting. The foil sample was prepared from the flat side of the centre of the sample surface.

Alternating magnetic treatment was applied by placing the samples in a magnetiser. Figure 2a displays the magnetic field direction for the samples. The treatment duration lasted 30 minutes. The registration of the magnetic field without a specimen in the magnetizer is presented in Figure $2 \mathrm{~b}$. The magnetic flux density recorded without the sample was 1.24 Tesla and during processing, the magnetizer settings were kept constant. The magnetic flux density was measured using a Hirst GM08 Gaussmeter; registration of the magnetic flux density was carried out using a Picoscope 4224 digital oscilloscope. Temperature measurements during treatment were conducted using a K-type thermocouple. The temperature rise recorded for the EN8 steel samples during treatment was $15.2^{\circ} \mathrm{C}$.

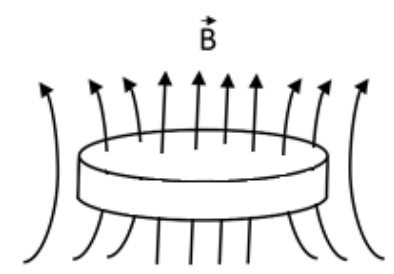

(a)

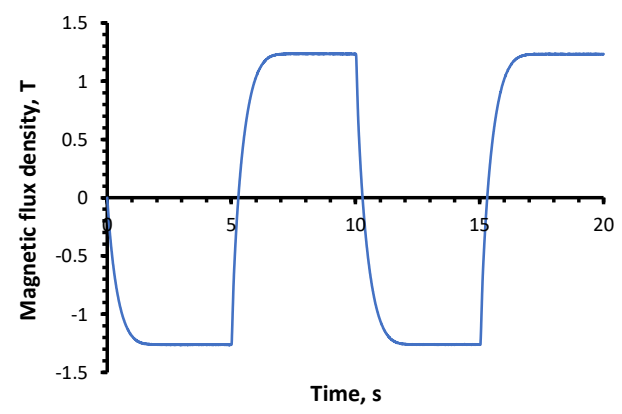

(b)

Figure 2. Schematic of treatment for Pin-on-disc sample (a), magnetic flux density during treatment (b). 


\section{Results}

The results of the pin-on-disc tests for the treated and untreated EN8 steel are shown in Figure 3. The results in Figure $3 a$ and $3 b$ show that the coefficient of friction (COF) for the treated EN8 steel sample was lower than that for the untreated sample. After treatment, the average COF was reduced by $18 \%$. It is evident that after about 1 min into the test, the value of the COF for the untreated sample started to initially increase slowly and subsequently (after about $7 \mathrm{~min}$ ) to further increase at a much faster rate. After about $10 \mathrm{~min}$, the value had risen to about 0.92 and kept increasing gradually to above 1 . On the other hand, the value of the COF for the treated sample remained almost constant at around 0.6 for about $25 \mathrm{~min}$ and began to gradually increase thereafter. The specific wear rate for the treated sample was lower by about $41 \%$ in comparison to the untreated sample. Figure 4 presents SEM micrographs of the worn surfaces of untreated and treated EN8 steel after the pin-on-disc tests, while Figure 5 shows a comparison of the 2D surface profiles of the resulting wear tracks. The wear tracks for the untreated sample were deeper and slightly wider in comparison to those for the sample in the treated condition. From these observations, it is evident that the alternating magnetic treatment had resulted in improvement of the wear resistance of EN8 steel. In order to understand the reasons for the observed behaviour, microhardness and RS measurements were undertaken which, along with measurements of the average wear scar width (from SEM) and surface roughness, are summarised in Table 1 and Table 2. The data show that after treatment there was $23 \%$ increase in the compressive RS in the samples. This observation is supported by the fact that there was a slight (5\%) increase in microhardness after treatment. Another important observation is that following the treatment, there was a reduction in the wear scar width by about $12 \%$ and a decrease of the average surface roughness of the wear tracks by $30 \%$.

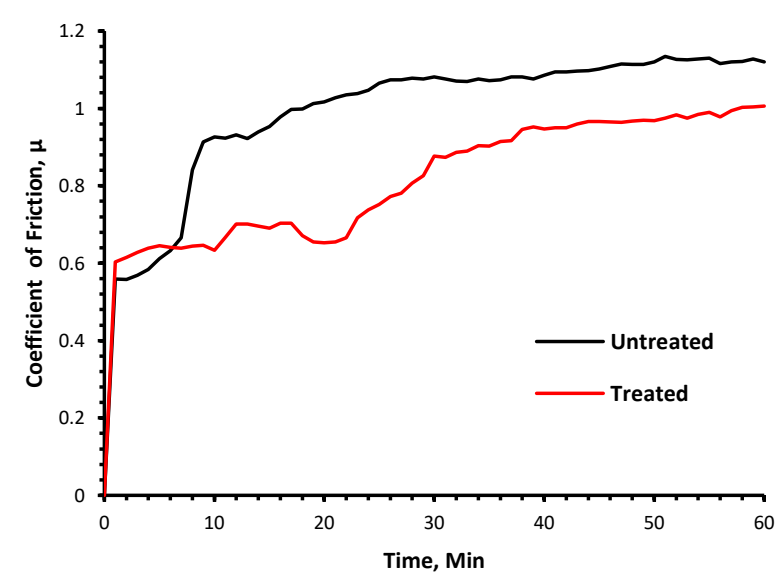

(a)

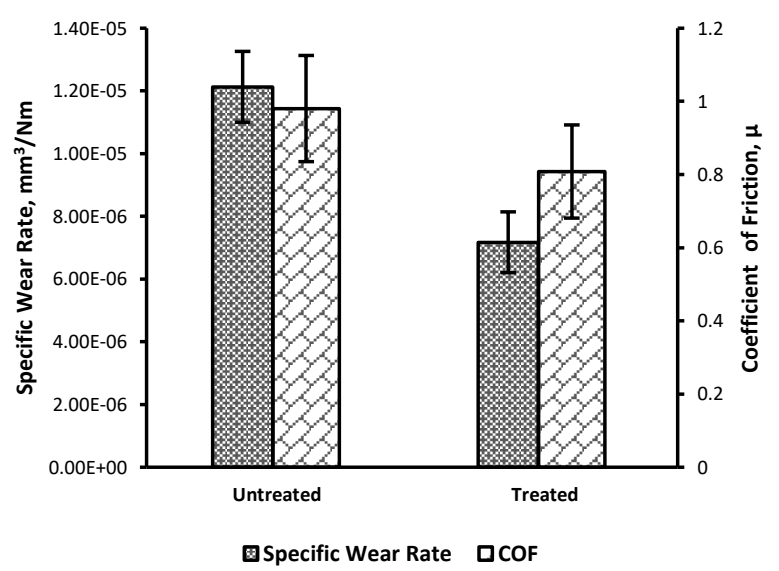

(b)

Figure 3. Variation of the COF of EN8 steel under lubricated conditions for untreated and treated disc specimens (a) and specific wear rate and average COF for untreated and treated specimens (b). The plots for Fig. 3(b) are based on average values from test results for 3 specimens of each condition. The measurements of COF values were taken starting 1 min into the test. 
Table 1. Mean (M) and mean-square deviation (MSD) of microhardness, wear track width and surface roughness.

\begin{tabular}{|c|c|c|c|c|c|c|c|}
\hline \multicolumn{2}{|c|}{ Sample condition } & \multicolumn{2}{c|}{${\text { Microhardness }{ }^{1}, \mathrm{HV}}^{2}$} & \multicolumn{2}{c|}{ Wear scar width ${ }^{2}, \mu \mathrm{m}$} & \multicolumn{2}{c|}{ Surface roughness $\mathrm{R}_{\mathrm{a}}{ }^{3}, \mu \mathrm{m}$} \\
\cline { 3 - 8 } & M & MSD & M & MSD & M & MSD \\
\hline \multirow{3}{*}{ EN8 Steel } & Untreated & 268.8 & \pm 12.4 & 316.7 & \pm 5.1 & 0.532 & \pm 0.121 \\
\cline { 2 - 8 } & Treated & 282.9 & \pm 10.1 & 283.2 & \pm 5.5 & 0.373 & \pm 0.031 \\
\hline
\end{tabular}

${ }^{1}$ Average values from data from 3 samples for each condition by taking measurements from 40 indentations per sample; ${ }^{2,3}$ Average values from data from 3 samples per condition by taking 4 measurements (one measurement in every quadrant) per sample.

Table 2. Mean (M) RS and mean-square deviation (MSD) of RS.

\begin{tabular}{|c|c|c|c|c|}
\hline \multirow{2}{*}{ EN8 Steel } & \multicolumn{2}{|c|}{ Untreated } & \multicolumn{2}{c|}{ After treatment } \\
\cline { 2 - 5 } & $\mathrm{M}(\mathrm{MPa})$ & $\begin{array}{c}\mathrm{MSD} \\
(\mathrm{MPa})\end{array}$ & $\mathrm{M}(\mathrm{MPa})$ & $\mathrm{MSD}(\mathrm{MPa})$ \\
\hline Sample 1 & -252 & \pm 79.9 & -319.9 & \pm 39 \\
\hline Sample 2 & -290.7 & \pm 20.2 & -346.2 & \pm 25.7 \\
\hline
\end{tabular}

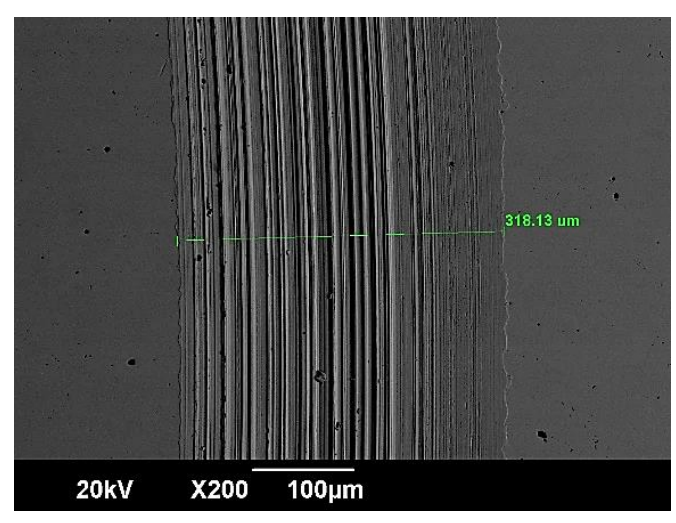

(a)

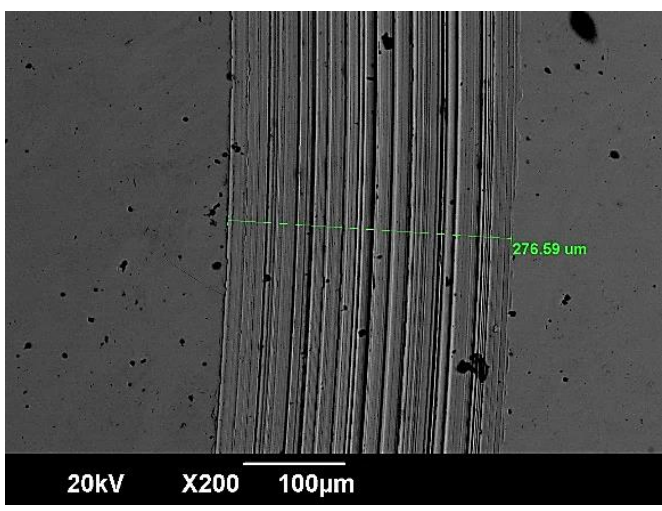

(b)

Figure 4 SEM wear tracks of the surface of (a) untreated and (b) treated EN8 steel after 1 hour

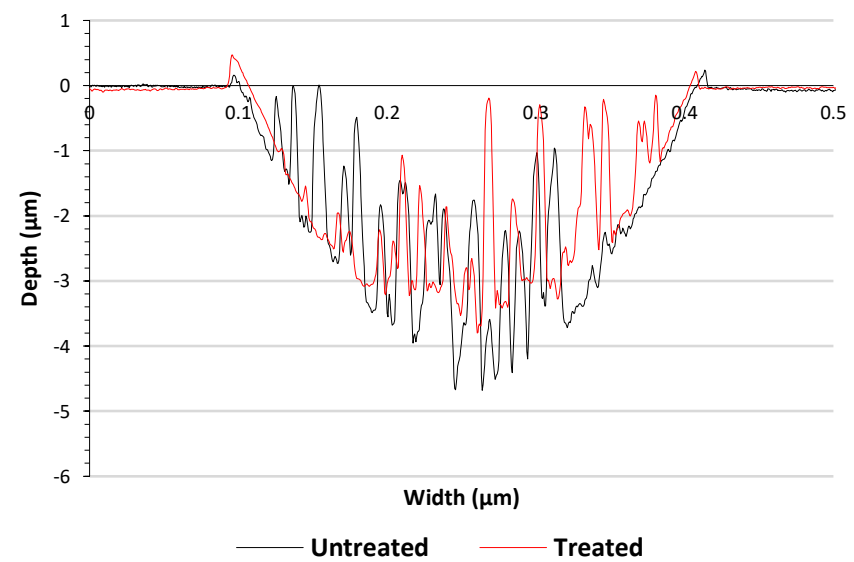

Figure 5. Comparison of the 2D surface profile of untreated (black) and treated (red) under lubricated condition. 
In order to further understand the effect of the treatment, hardness and $\mathrm{H}^{3} / \mathrm{E}^{2}$ ratio measurements were obtained from nanoindentation tests and the results are presented in Figure 6a. In both cases they show an increase following alternating magnetic field treatment. The hardness has increased by $30 \%$ after application of the treatment, while the $\mathrm{H}^{3} / \mathrm{E}^{2}$ ratio which represents the resistance to plastic deformation has increased by $118 \%$. Loading and unloading curves were also obtained from the nanoindentation tests and are shown in Figure 6b.

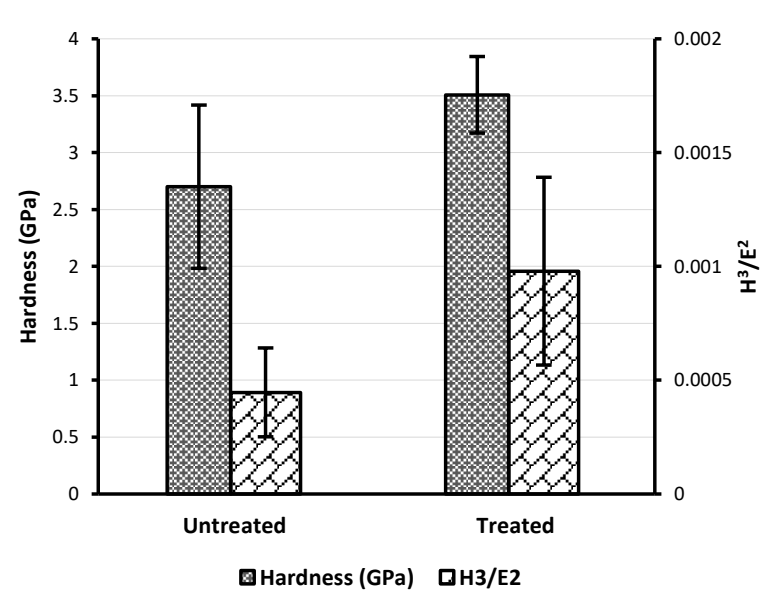

(a)

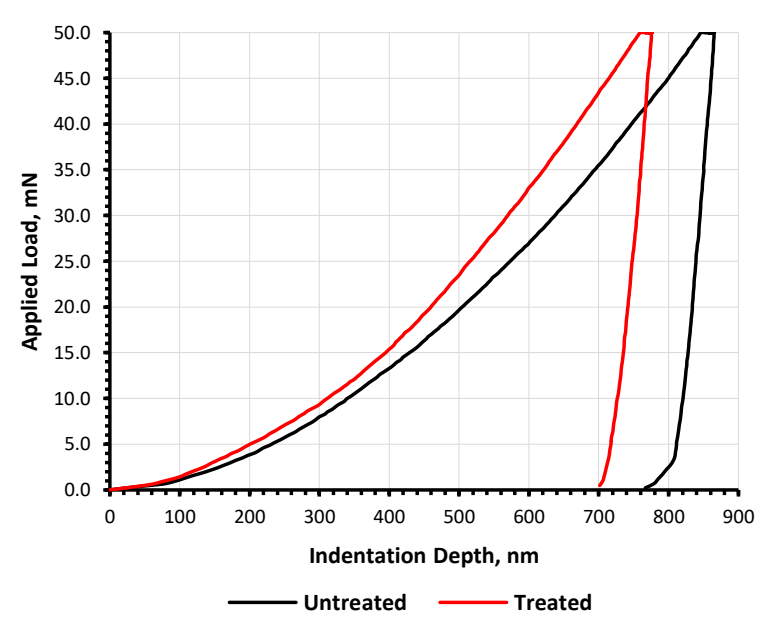

(b)

Figure 6. Nanoindentation results of hardness and $\mathrm{H}^{3} / \mathrm{E}^{2}$ ratio with standard deviation error bars (a) and loading and unloading curve for treated and untreated EN8 steel (b).

The MFM results in Figure 7a and Figure 7b show the magnetic domain structure of an untreated EN8 steel sample which subsequently underwent alternating magnetic field treatment. The MFM scans were taken from exactly the same area of the sample before and after treatment. From the results, it is evident that after treatment there appears to be more magnetization and alignment of the magnetic domains within the sample. Furthermore, the magnetic domain structure after treatment appears more homogeneous than in the untreated sample. 


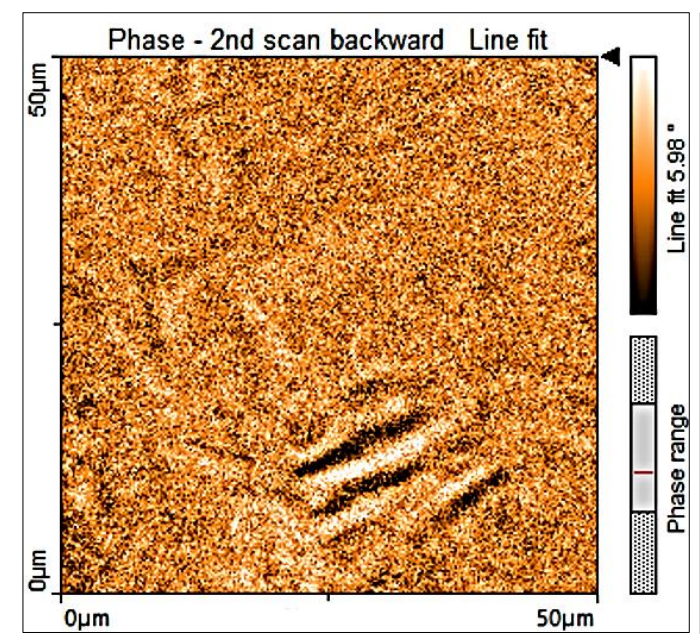

(a)

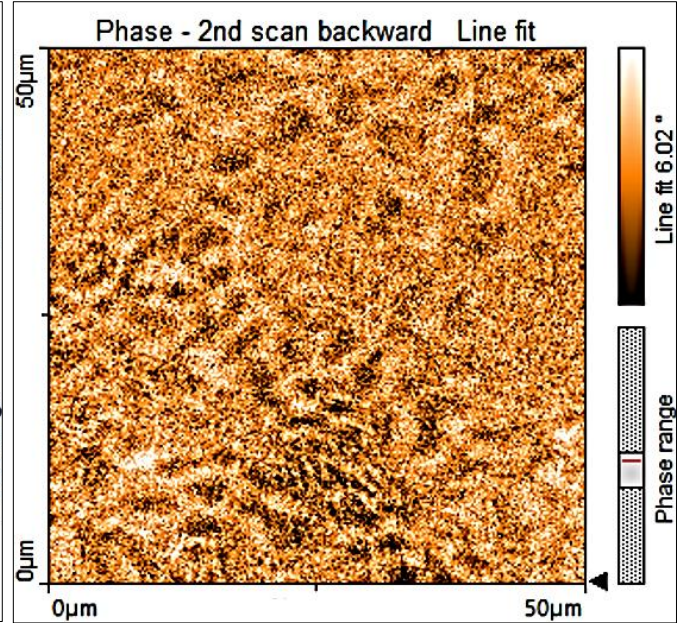

(b)

Figure 7. Magnetic domain structure of untreated (a) and treated EN8 steel (b).

The results of TEM examination of an untreated EN8 steel sample in Figure 8a show local areas of high-density of dislocation structures including dislocation tangles and pile-ups along grain boundaries. Following the alternating magnetic field treatment, redistribution of dislocations has been observed to take place as shown in Figure $8 \mathrm{~b}$. In addition, there appeared to be a reduction in the entanglement and pile up of dislocations at the grain boundaries as the concentration of the dislocations became less localised. These observations provide evidence to suggest that the treatment facilitates the movement of dislocations.

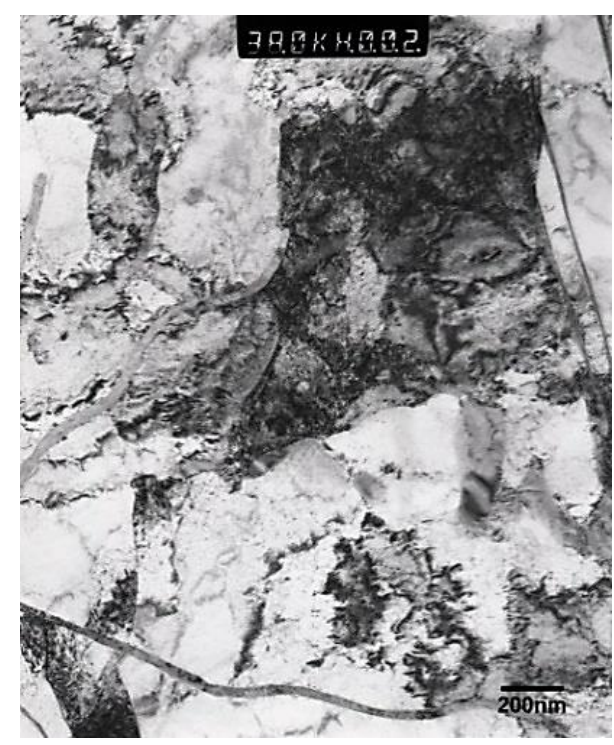

(a)

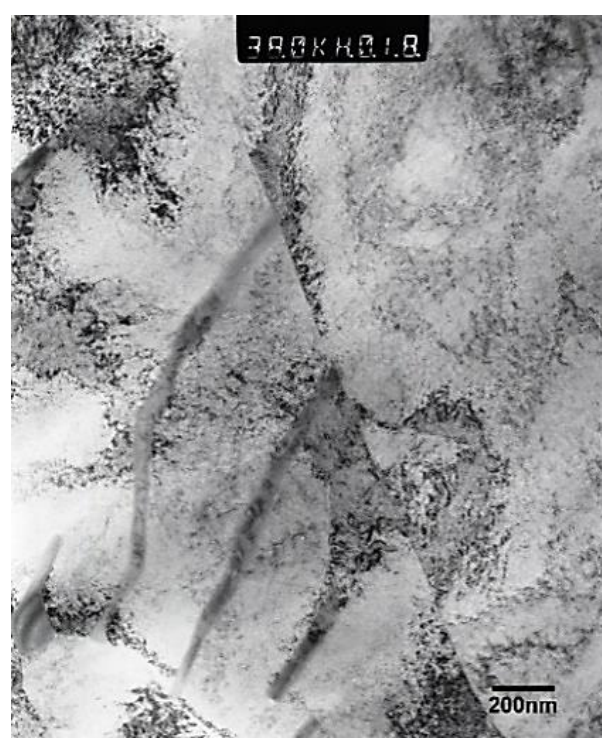

(b)

Figure 8. TEM images of untreated (a) and treated (b) EN8 Steel. 


\section{Discussion}

The present study has shown evidence of improvement in the wear and friction properties of EN8 steel as a result of alternating magnetic field treatment. Figure 3a shows that the COF for the untreated sample was rather unstable and was higher than that for the treated sample. In Figure $3 \mathrm{~b}$ it is shown that the specific wear rate was higher for the untreated samples. The worn surface of the untreated samples exhibited greater roughness as well as deeper ploughing grooves with evidence of abrasive wear. In order to understand the reasons for the difference in the wear and friction characteristics of the two sets of samples, nanoindentation tests were carried out to evaluate the mechanical properties at the surface of the EN8 steel. The nanoindentation results revealed that following the treatment there was an increase in both the hardness and the $\mathrm{H}^{3} / \mathrm{E}^{2}$ ratio. These results suggested that after treatment the resistance of EN8 steel to plastic indentation had increased and thus the steel exhibited lower wear. At the same time the loading-unloading results showed a small increase in the elastic recovery parameter from $4.30 \%$ to $5.07 \%$ following treatment. This implied that the contact between the pin and the EN8 steel had become less plastic and more elastic leading to lower abrasion wear and to a more stable COF resulting to a lower wear rate.

The main factor that has contributed to the increase in resistance to plastic deformation of the EN8 steel is the increase in compressive RS (and consequently surface hardness). The effects of RS and hardness on wear behaviour are wellknown [11, 24-28] and are conventionally achieved by heat-treatment, coating and shot-peening. However, in the present investigation, a process based on the application of an alternating magnetic field has been used instead. Such a technique may be attractive in that it is fast and cost-effective; for its successful development it is important to understand the mechanism leading to changes in the RS and hardness of metals. First of all, the effect of the external parameters on EN8 steel need to be addressed. The effects arise not only from the alternating magnetic field, but also from the resulting eddy currents that were induced into the sample during the transition change of the magnetic field polarity which occurred every 5 seconds. Thus, the samples were exposed to both an alternating magnetic field and a pulsed electric current during processing. QuickField 6 software (Tera Analysis, Svendborg, Denmark) was employed in order to obtain the eddy current distribution on the surface of the sample. The solution that was obtained was based on a 2D formulation of a transient magnetic field problem. The physical properties used for the finite element analysis are presented in Table .

Table 3. Physical properties of materials used during modelling.

\begin{tabular}{|c|c|c|c|c|c|}
\hline \multicolumn{1}{|c|}{ Property } & Core (steel) & Spacer (steel) & Winding wire (copper) & EN8 steel sample & Surrounding air \\
\hline Conductivity, MS/m & 10 & 10 & 56 & 10 & 0 \\
\hline Relative permeability & B-H curve* & B-H curve* & 1 & B-H curve* & 1 \\
\hline
\end{tabular}

*The magnetic flux density vs magnetic field strength (B-H) curve for steel was taken from [29]

The full current time variation, $I(t)$, passing through one turn of magnetizer windings can be presented by the following equation:

$$
I(t)=I_{0} \operatorname{sign}(\sin (2 \pi t / T))
$$


where $T$ is the period of time that the field acts in both directions of the magnetizer ( $10 \mathrm{~s}$ as shown in Figure $2 \mathrm{~b}$ ). The value of $I_{0}$ was determined based on the best fitting of the calculated and registered profiles of the magnetic flux density for the magnetizer in the absence of a sample; according to the results shown in Figure $2 b$, the value of the magnetic flux density was 1.24T. Modelling was fulfilled for the magnetizer with an EN8 steel sample located at the centre of the magnetizer. Figure 9 shows a $1 / 2$ geometrical model of the treatment arrangement that was used for the numerical modelling.

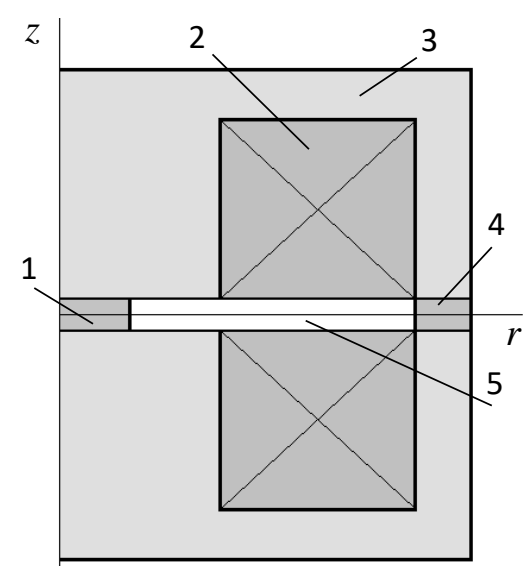

Figure 9. Scheme of axisymmetric model used at numetical modelling: 1 - disc sample, 2 - winding; 3 - magnetiser core; 4 - steel spacer of $3 \mathrm{~mm}$ thickness, 5 -air, $z$-axis; $r$ - radius.

According to the modelling results, during the treatment the EN8 steel sample was exposed to a magnetic flux density of about $2.58 \mathrm{~T}$ as it is magnetized under an external magnetic field. The distribution of the maximum eddy currents along the radius of a flat surface of the sample at the moment of change of polarity is presented in Figure 10. The results show that the change of polarity of the external magnetic field causes an induction of eddy currents on the flat sample surface with maximum current density of $5.2 \times 10^{6} \mathrm{~A} / \mathrm{m}^{2}$ near the outer radius of the sample and a minimum value of $0.26 \times 10^{6} \mathrm{~A} / \mathrm{m}^{2}$ near its centre.

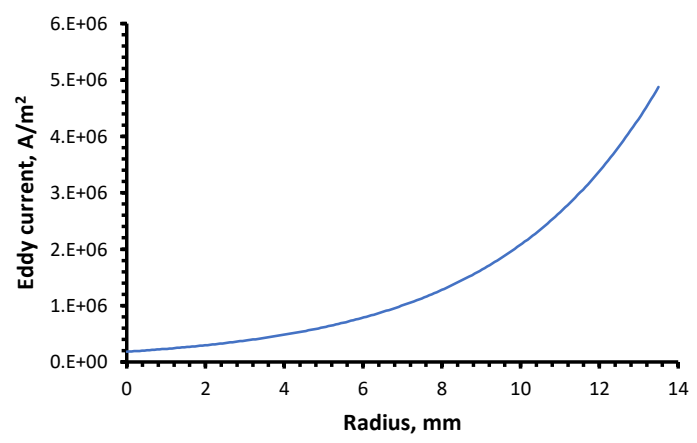

Figure 10. Distribution of maximum eddy current along radius on flat surface of the sample during the change of polarity.

Previous studies [30,31] have shown that notable changes in the mechanical properties and redistribution of residual stresses and their relaxation can take place when the electric current density exceeds a value of $10^{8} \mathrm{~A} / \mathrm{m}^{2}$. Clearly the value of the calculated current density from the numerical modelling is significantly lower than the threshold level that needs to be exceeded for changes in the mechanical properties to take place. Some researchers [32-34] have demonstrated that the application of a magnetic field can lead to relaxation and redistribution of residual 
stresses in ferromagnetic steels by activating dislocation movement. Pinned dislocations can become unpinned and move more easily due to the presence of stored energy (mainly in the form RS) that is caused during processing (cold rolling, drawing, welding, etc.) This stored energy in manufactured metal components can be relatively high and has been shown to reach up to $60 \%$ of the work of the initial plastic deformation within the alloy [35].

In the present study that used the application of an alternating magnetic field to the EN8 steel, the depinning of dislocations due to domain rotation [1] is most likely to have occurred. The periodic magnetization of steel up to 2.58T, which according to the simulation took place during the treatment, is sufficiently high to cause magnetic saturation of the steel with gradual alignment of the magnetic domains. In addition, there is motion of the domain walls and expansion of the volume of those domains that have the largest magnetic moment coinciding with the direction of the external magnetic field. Under the treatment, the magnetic field alternates in the opposite direction and this causes reorientation of the magnetic domains. A change in the appearance of the domain structure before and after the treatment as shown from the MFM scans in Figure 7, indicates significant changes in the domain structure of the material during the treatment. As magnetic domain walls are pinned by dislocations [36], the reversible rotation of the domains can trigger dislocation depinning from their quasi-stable states and lead to further motion that is driven by the stored energy in the cold-rolled EN8 steel. An additional factor that can trigger dislocation depinning is the magnetostriction of the samples due to the application of the magnetic field [32, 37].

The TEM images presented in Figure 8 indicate a reduction in the dislocation pile-up at the grain boundaries and a more even dislocation distribution following the treatment. This confirms facilitation of the mobility of dislocations due to the magnetic field. The increased dislocation mobility within the near-surface region caused dislocation movement to the outer surface of the sample as the surface is a natural sink for the dislocations. This, in turn, caused increased straining at the surface layer of the material and led to the creation of more compressive residual stresses as detected by XRD (see Table 1) and to higher micro/nano hardness [38, 39]. The factors were responsible for the increase in the resistance against abrasive wear following the application of the alternating magnetic field treatment. The TEM results also show that the movement of dislocations creates a more homogeneous and less localised dislocation structure at the sample surface. The MFM results have revealed a more uniform distribution of magnetic domains, while the microhardness and RS measurements exhibit a lower mean-square deviation. These observations suggest that, in addition to improved hardness, there is evidence of microstructural homogenisation at the sample surface following the alternating magnetic treatment and that this also has a role in improving resistance to wear and reduction of the COF.

\section{Conclusions}

In this experimental study the effect of alternating magnetic field treatment on the friction/wear resistance of EN8 steel alloy was investigated. The following conclusions can be made:

1. A series of mechanical and tribological experiments were carried out on treated and untreated EN8 steel. Observations show that the values of the specific wear rate, wear scar width and coefficient of friction for the treated were lower than those for the untreated sample as a result of a treatment. 
2. The EN8 steel exhibited improved microhardness and nanohardness after alternating magnetic field treatment, while the XRD RS analysis revealed an increase in compressive residual stresses in the near-surface layers.

3. TEM analysis indicated that there was a reduction in the dislocation pile up and a more uniform dispersion of dislocations in the treated samples.

4. The alternating magnetic field treatment was accompanied by changes in magnetic field direction and in magnetic polarity and had a non-thermal effect leading to dislocation depinning and to increased mobility of dislocations towards the outer surface of samples. This gave rise to an increase in the compressive stresses and to an increase in microhardness which are responsible for the improved wear resistance and reduction of the coefficient of friction.

\section{Acknowledgement}

This research was supported by the Marie Curie International Incoming Fellowship scheme within the 7th European Commission Framework Programme Grant number PIIF-GA-2010-274324.

\section{References}

1. Çelik, A., et al., Effect of magnetic treatment on fatigue life of AISI 4140 steel. Materials \& Design, 2005. 26(8): p. 700-704.

2. Yetim, A., et al., The effect of magnetic field on the wear properties of a ferromagnetic steel. Wear, 2013. 301(1-2): p. 636-640.

3. Murugappan, S. and S. Arul, Effect of Cryogenic Pre cooling on Chip Reduction Co-efficient during Turning of EN8 Steel Rod. Materials Today: Proceedings, 2017. 4(8): p. 8848-8855.

4. Ludema, K.C. and L. Ajayi, Friction, wear, lubrication: a textbook in tribology. 2018: CRC press.

5. Bajwa, R., et al., Wear and Friction Properties of Electrodeposited Ni-Based Coatings Subject to Nano-enhanced Lubricant and Composite Coating. Acta Metallurgica Sinica (English Letters), 2016. 29(10): p. 902-910.

6. Borisova, E.A. and V.V. Zelinskiy, On the Mechanism of Ferromagnetic Materials Wear Reduction. Procedia Engineering, 2015. 129: p. 111-115.

7. Gao, F.M., et al., In situ observation of the magnetic domain in the process of ferroalloy friction. Tribology International, 2016. 97: p. 371-378.

8. Han, X., et al., Tribological behavior of shot peened/austempered AISI 5160 steel. Tribology International, 2020. 145: p. 106197.

9. Subbiah, R., et al., Influence of dry sliding wear behavior and assessment of properties on treated AISI310 SS material by gas nitriding process. Materials Today: Proceedings, 2020.

10. Subbiah, R., V. Vinod Kumar, and G. Lakshmi Prasanna, Wear analysis of treated Duplex Stainless Steel material by carburizing process - A review. Materials Today: Proceedings, 2020.

11. Yan, W., et al., Effect of surface work hardening on wear behavior of Hadfield steel. Materials Science and Engineering: A, 2007. 460-461: p. 542-549.

12. Hiratsuka, K. and T. Sasada, Wear of metals in a magnetic field. Wear, 1993. 160(1): p. 119-123.

13. Gao, F. and J. Fan, Research on the effect of remanence and the earth's magnetic field on tribo-magnetization phenomenon of ferromagnetic materials. Tribology International, 2017. 109: p. 165-173.

14. Muju, M.K. and A. Ghosh, A model of adhesive wear in the presence of a magnetic field - I. Wear, 1977. 41(1): p. 103-116.

15. Bockstedt, J. and B.E. Klamecki, Effects of pulsed magnetic field on thrust bearing washer hardness. Wear, 2007. 262(9-10): p. 1086-1096.

16. Babutskyi, A., A. Chrysanthou, and C. Zhao, Effect of pulsed magnetic field pre-treatment of AISI 52100 steel on the coefficient of sliding friction and wear in pin-on-disk tests. Friction, 2014. 2(4): p. 310-316.

17. Xi, X., Y. Xia, and Y. Hu, The Effects of Magnetic Treatment on the Tribological Behavior of AISI 1045 Steel under Lubricated Conditions. Tribology Transactions, 2018. 61(4): p. 671-682. 
18. Wei, Y., et al., Magnetic-field tribological behaviors of aluminum-alloy and steel. AIP Advances, 2018. 8(11): $p$. 115014.

19. Stolarski, T.A. and Y. Makida, Influence of magnetic field on wear in high frequency reciprocating sliding contacts. Tribology International, 2011. 44(9): p. 1004-1013.

20. Han, H., et al., Effect of DC magnetic field on friction and wear properties of 45 steel at different velocities. Tribology Letters, 2016. 64(3): p. 38.

21. Wei, Y., et al., Impact of material permeability on friction and wear Properties under the interference of $D C$ steady magnetic field. Tribology International, 2013. 57: p. 162-169.

22. Tharajak, J. and D. Nicomrat. Friction Coefficient and Worn Surface of Ferromagnetic Materials under Magnetic Fields. in Applied Mechanics and Materials. 2016. Trans Tech Publ.

23. Cseh, D. and V. Mertinger, X-Ray Diffraction Measurements of Residual Stress Induced by Surface Compressing Methods. Vol. 729. 2012. 199-204.

24. Stachowiak, G. and A.W. Batchelor, Engineering tribology. 2013: Butterworth-Heinemann.

25. Bhushan, B., Introduction to tribology. 2013: John Wiley \& Sons.

26. Fridrici, V., S. Fouvry, and P. Kapsa, Effect of shot peening on the fretting wear of Ti-6Al-4V. Wear, 2001. 250(1): p. 642-649.

27. Mitrovic, S., et al., Friction and wear behavior of shot peened surfaces of 36CrNiMo4 and 36NiCrMo16 alloyed steels under dry and lubricated contact conditions. Applied Surface Science, 2014. 290: p. 223-232.

28. Oshida, Y., Chapter 11 - Surface Modifications, in Bioscience and Bioengineering of Titanium Materials, Y. Oshida, Editor. 2007, Elsevier: Oxford. p. 311-379.

29. Magweb, Free BH Curves - Magweb. Magweb.

30. Baranov, Y.V., et al., Physical bases of electric-pulse and electroplastic treatments and new materials. Chap, 2001. 1: p. 56-77.

31. Troitskii, O., et al., Application of high-density current in plastic working of metals. physica status solidi (a), 1979. 52(1): p. 85-93.

32. Klamecki, B.E., Residual stress reduction by pulsed magnetic treatment. Journal of Materials Processing Technology, 2003. 141(3): p. 385-394.

33. Cai, z. and X. Huang, Residual stress reduction by combined treatment of pulsed magnetic field and pulsed current. Materials Science and Engineering: A, 2011. 528(19-20): p. 6287-6292.

34. Tang, F., et al., Research on residual stress reduction by a low frequency alternating magnetic field. Journal of Materials Processing Technology, 1998. 74(1-3): p. 255-258.

35. Oliferuk, W., S.P. Gadaj, and M.W. Grabski, Energy storage during the tensile deformation of armco iron and austenitic steel. Materials science and engineering, 1985. 70: p. 131-141.

36. Jiles, D., Introduction to magnetism and magnetic materials. 2015: CRC press.

37. Tang, G., et al., Effect of a pulsed magnetic treatment on the dislocation substructure of a commercial high strength steel. Materials Science and Engineering: A, 2005. 398(1-2): p. 108-112.

38. Frankel, J., A. Abbate, and W. Scholz, The effect of residual stresses on hardness measurements. Experimental Mechanics, 1993. 33(2): p. 164-168.

39. Jang, J.I., Estimation of residual stress by instrumented indentation: A review. J. Ceram. Process. Res, 2009. 10(391): p. 1996-1944. 